\title{
"Effectiveness of Planned Health Teaching Programme on Knowledge Regarding Care of Pressure Sores Among Caregivers of Non-Ambulatory Clients"
}

\author{
Maneesh Sharma ${ }^{1}$, Himanshu Vyas ${ }^{2}$, Vijay Purbia ${ }^{3}$ \\ ${ }^{I}$ Nursing Tutor, All India Institute of Medical Science, Rishikesh (Uttarakhand)) \\ ${ }^{2}$ Nursing Tutor, All India Institute of Medical Sciences, Jodhpur, Rajasthan \\ ${ }^{3}$ Lecturer, Geetanjali College of Nursing, Udaipur, Rajasthan
}

\begin{abstract}
A Quasi experimental study was conducted to assess the effect of planned health teaching on knowledge regarding care of pressure sore among caregivers of non ambulatory client's in selected hospital of PCMC area in Pune city. The samples consisting of 60 Caregivers of Non-Ambulatory client's was selected by using a simple random sampling technique. The tool comprises of knowledge questionnaires. The pre-test was conducted and planned health teaching was administered on caregiver's of non-ambulatory client's immediately after the pre-test.the post test was conducted after one week of pre testwith same questionnaires. The data obtained were analyzed using descriptive and inferential statistics. In pre-test the sampled subjects were having poor knowledge regarding care of pressure sore i.e. about $41 \%$. and in the post-test the sampled subject had an improved knowledge regarding care of pressure sore.i.e. about $100 \%$. In relation to Planned teaching program, the paired " $t$ " test showed that, the teaching program was statistically significant at $p<0.0001$ level in caregiver's of nonambulatoryclient's. These data proved that the knowledge of caregiver's of nonambulatory client's had been markedly increased after the administration of planned teaching program
\end{abstract}

Keywords: Caregiver's, Non-ambulatory, Pressure sore , Knowledge

\section{Introduction}

The integument, or skin, makes up $15 \%$ to $20 \%$ of the body's weight. Intact skin is the body's primary defence system. It protects us from invasion by organisms, helps to regulate body temperature, manufactures vitamins and provides our external appearance. Skin is integral to self image and self esteem. Each individual's unique appearance is established through the skin. As the largest and most visible organ of the body, the skin plays a major role in our physical and mental health and protects us from an array of natural and man- made attacks. Yet the skin is rarely taken as seriously as other organ systems, such as heart and lungs.

474,692 new cases of Pressure ulcer occurred in the US 2000-2002. 29.86 per 1,000 hospitalized patients are at risk for developed Pressure ulcers in America. 13.13\% of Pressure ulcers resulted in death in the US in the year 2000-2002. Estimated 21.564 Pressure ulcers occurred per 1,000 hospital discharges after stays of 4 or more days (excluding paralysis patients, neonates and long-term-care facility patients) in the US in the year 2000. Estimated 7.67 Pressure ulcers occurred per 1,000 hospital discharges after stays of 4 or more days (excluding paralysis patients, neonates and long-term-care facility patients) of people aged 0 to 17 in the US in the year 2000. Estimated 4.952 Pressure ulcers occurred per 1,000 hospital discharges after stay of 4 or more days (excluding paralysis patients, neonates and long-term-care facility patients) of people aged 18 to 44 in the US in the year 2000. Estimated 9.839 Pressure ulcers occurred per 1,000 hospital discharges after stay of 4 or more days (excluding paralysis patients, neonates and long-term-care facility patients) of people aged 45 to 64 in the US in the year 2000. Estimated 25.172 Pressure ulcers occurred per 1,000 hospital discharges after stay of 4 or more days (excluding paralysis patients, neonates and long-term-care facility patients) of people aged over 65 in the US in the year 2000.

Pressure ulcers are a widespread and often underestimated health problem. Pressure ulcers are a complex clinical problem with a multifactorial aetiology. They are nationally and internationally recognized as an adverse outcome of admission to a health care facility and as 1 of the 5 most common causes of harm to patients. In addition, pressure ulcers are key clinical indicators of the standard and effectiveness of care. Despite recent major technical advances in health care, pressure ulcers still occur at unacceptable rates within health care facilities, even though such ulcers are largely preventable. Pressure ulcers are a significant problem in institutionalized elderly patients and critically ill\& terminally ill patients, causing pain, decreasing quality of life, and leading to significant morbidity and prolonged hospital stays. Prevalence and incidence estimates vary by setting, ulcer stage, and length of follow-up. 
The incidence of developing pressure sores are increasing so there is need to increasing effort to curb or make people or caregivers aware about identification, prevention \& care of pressure sore. Therefore the investigator thought to conduct the Research study regarding care of pressure sore among Caregiver's of Non Ambulatory client's .

The Problem statement:

\section{Research Elaborations}

A Study to Assess the effectiveness of planned health teaching on knowledge regarding care of pressure sore among caregiver's of non- ambulatory client's in selected Hospitals of Pune City.

\section{Objectives}

1. To Asses the level of knowledge regarding care of pressure sore among caregivers of non ambulatory clients.

2. To determine the effect of planned health teaching regarding care of pressure sores among caregiver's of non ambulatory client's.

3. To find an association between level of knowledge of caregivers and selected demographic variables.

\section{Hypotheisis}

Level of significance chosen for the entire hypothesis was 0.05 level of Significance

Ho: There will be no significance difference between pre test\&post test knowledge of caregivers regarding care of pressure sores.

H1: There will be significance difference between pre test\&post test knowledge of caregivers regarding care of pressure sores.

\section{Material And Methods}

Population: Caregiver's of non ambulatory client's

Samples: Caregiver's of Non Ambulatory client's from 2 Hospitals at Pune City

Sample size: 60 Caregiver's .

Setting: 2 hospitals at Pune City, Maharashtra

Conceptual framework - Conceptual framework is based on supportive educative system based on Orem's self care theory.

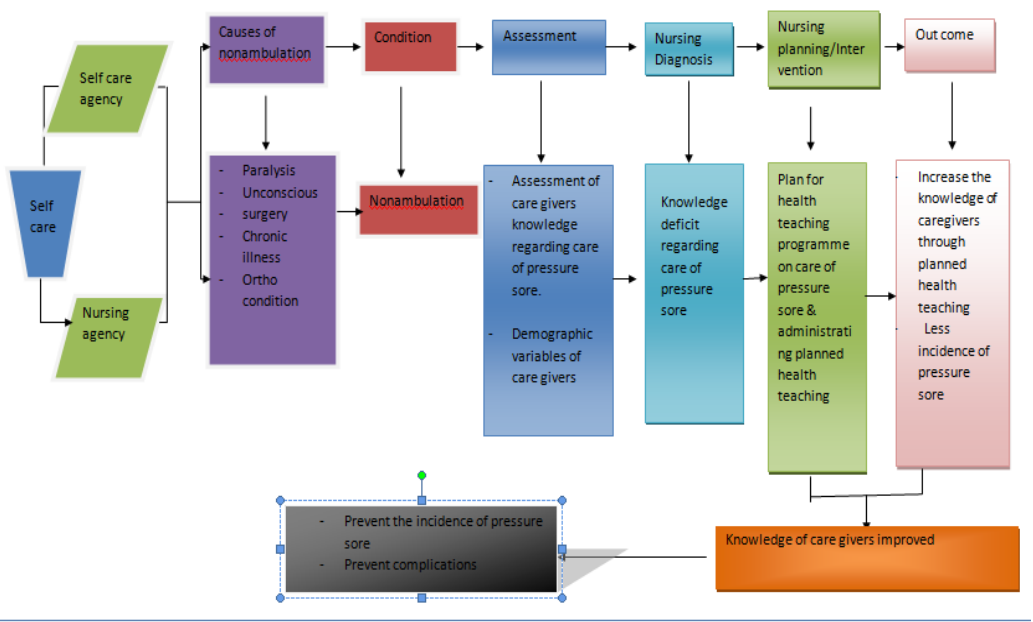

Conceptual Framework- Based Orem's Self care deficit 


\section{Research Design} test design.

The research design selected for the present study was quasi experimental one group pretest and post

\begin{tabular}{|l|l|l|}
\hline Pre test & Treatment & Post test \\
\hline Knowledge & Planned Teaching Programme & Knowledge \\
\hline O1 & X & O2 \\
\hline
\end{tabular}

Table -1 : Quasi experimental One group Pretest Post test design

O1- Pretest X- Intervention O2- Post test

Variables under study -

Independent variable - Planned teaching programme

Dependent variable - Knowledge of caregivers

Demographic variables - Age,sex,occupation, educational qualification, income

Description of tool

The instrument used for this study is knowledge questionnaire, which was designed by the investigator. It consists of 3 parts.

Part I : Demographic variables -8 items

Part II: Knowledge questionnaire -20 items

Section A: Demographic data of the samples

Section B: Knowledge statements related to care of pressure sore among caregiver's of non -ambulatory client's.

$\underline{\text { Score interpretation }}$

$0-7 \quad-$ Poor

8-14 - Average

$15-20 \quad-$ Good

Data Collection:

After getting formal approval from the College Principal and the Hospital authorities the investigators started with data collection process. Structured knowledge questionnaire was used to collect data in the pretest as well as the post test. The data collection continued for around 1 month duration.

Results:

In the finding reveals that, majority $36.67 \%$ of caregivers were in the age group of $39-48$ years, $80 \%$ of them were male, $33.33 \%$ were educated up to secondary, and $31.67 \%$ were father and siblings as caregivers of clients and regarding medical data $36.7 \%$ clients were admitted in the hospital for the period of $16-30$ days, $90 \%$ of the caregivers previously have not taken care of the clients with pressure sore and $48.3 \%$ of clients were diagnosed as orthopedic problem.

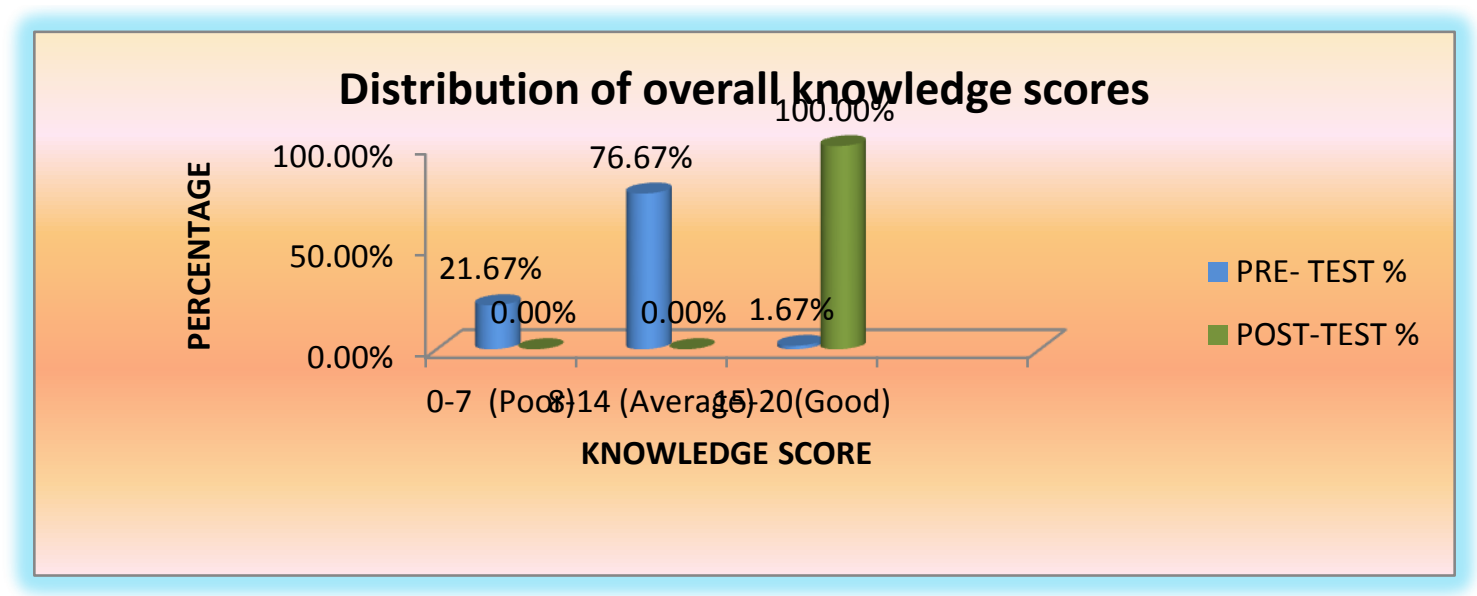

Figure-I Bar diagram showing Distribution of overall knowledge scores

Figure- I Showing the the analysis data related to knowledge of caregivers suggested that the maximum 76.67\% percentage of caregivers scored between 8-14 in pre test of knowledge regarding care of pressure sores 
and post test scores shows that all 60 caregivers scored (100\%) between $15-20$ in post test of knowledge regarding care of pressure sores.

\begin{tabular}{|c|c|c|c|c|c|}
\hline Test & Mean & SD & $\mathbf{T}$ & Df & $\begin{array}{l}\text { 'P' } \\
\text { value }\end{array}$ \\
\hline \multirow[t]{2}{*}{ Pre Test } & & & & & \\
\hline & 9.63 & 2.66 & & & \\
\hline Post Test & 18.12 & 1.14 & -24.48 & 59 & 0.000 \\
\hline
\end{tabular}

Table -2 Pretest\&Post test Knowledge score

The table 2 shows the summary of statisticdge that pre treatment knowledge average score is 9.63 and after health teaching average knowledge score rises to 18.12. To check whether this rise in average knowledge score is statistically significant or not, researcher applied paired t test. Since $p$ value is less than 0.05 ( $p$ value $=$ $0.00)$ there is significant difference in average knowledge score after teaching. Researcher can conclude that at $5 \%$ level of significance and 59 degrees of freedom there is significant rise in average knowledge score after teaching. Therefore researcher can conclude that teaching was effective.

Figure -2 Comparison of knowledge score of Pre-test \& Post -Test

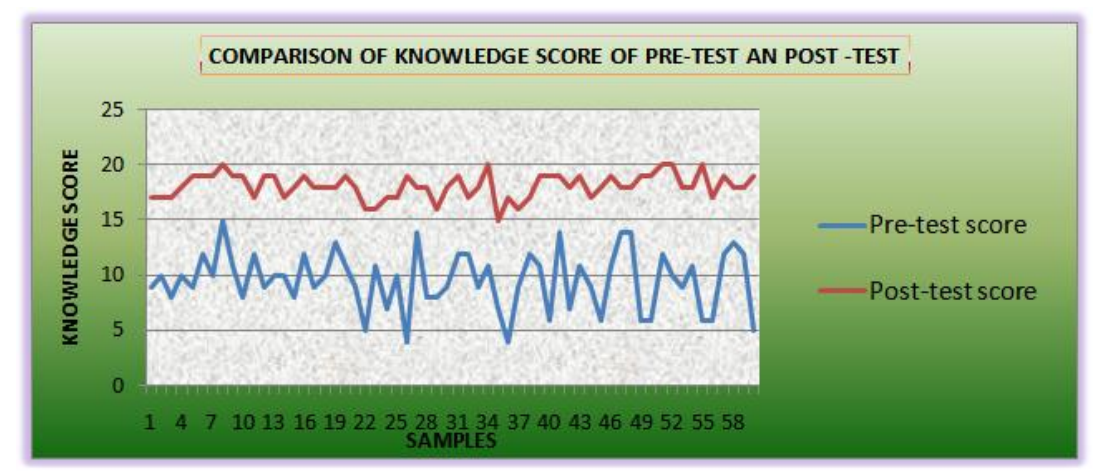

Figure 2 showing the calculated ' $\mathrm{P}$ ' value is 0.000 at 0.05 level of significance in all the category, which means there is significant difference between average values of pre and post test regarding care of pressure sores, which gives an interpretation that there is significant gain in knowledge score of the samples in the post-test phase. This indicates that the teaching is effective in increasing the knowledge of the samples regarding care of pressure sores. Hence Ho is rejected and $\mathrm{H} 1$ is accepted.

\begin{tabular}{|l|l|l|l|}
\hline S.No & Variables & \multicolumn{1}{|c|}{ p value } & Result \\
\hline 1. & Age & 0.476 & No association \\
\hline 2. & Sex & 0.301 & No association \\
\hline 3. & Education & 0.275 & No association \\
\hline 4. & Relation & 0.874 & No association \\
\hline
\end{tabular}

Table- 3 Association with Demographic Variables

Since the $\mathrm{P}$ value is more than 0.05 in all the demographic variables so there was no significant association between knowledge score and demographic variables.

\section{Vii Conclusion}

The conclusion drawn from the findings of the study are as follows:

The ' $t$ ' test done to find the effect of teaching on knowledge among caregivers of non ambulatory clients regarding care of pressure sores revealed that there is highly significant gain in knowledge of caregivers in the post test who had been supplemented with the planned Health teaching related to care of pressure sore.

The correlation finding was done to find the relationship of increase in knowledge level with selected demographic variables, by using one way ANNOVA test and calculating the ' $p$ ' value.

Educating the caregivers on care of pressure sore especially by the use of planned teaching has shown a significant effect in improving their knowledge. The study done is an attempt to increase the knowledge of caregivers regarding care of pressure sore . 
The present study can be justified on the fact that most of the time caregivers have to deal with the problems of pressure sore clients without any professional support. In today's world with emergence of nuclear families and husband and wife working, pressure sore prone clients are not being given enough quality care so that they developed pressure sores. So an appropriate intervention by the caregivers can help the clients to prevent development of pressure sores and provide care as well.

The nurse patient ratio is poor in Indian setup hence most of the time, are dependent on the caregivers to meet the basic needs of the clients. It is very often caregivers in hospital setup who are involved in care of non ambulatory clients with pressure sores. To provide proper care it is necessary for them to have adequate knowledge about care of pressure sores. The nurse must assist the caregivers, prepare them to adjust adequately and help the patients to achieve the optimal level of function so that after discharge from hospital caregiver's can provide care to the client's with pressure sore.

Administrating planned health teaching regarding care of pressure sores to the caregivers of non ambulatory clients has shown a significant effect in improving their knowledge. Thus, it helps for care of pressure sores by the caregivers and will lessen the problems faced by caregivers in caring the clients with pressure sores.

\section{References}

[1] Barbara K Timby; Fundamental Skills \& Concepts in patient care, 7thedition,Lippincott Williams \& wilkinsons,Pp-594, Pp 602604

[2] Beach, D.L. (1993); Gerontological caregiving: Analysis of family experience. Journal of Gerontological Nursing, 79(12), Pp 3541.

[3] Brunner \&Siddhart's;" Text book of Medical Surgical Nursing; 10th edition, lippincottwilliyams\&willkins, Pp 501-502.

[4] Canam, C, \& Acorn, S (1999); Quality of life for caregivers of people with chronic healthproblems Rehabilitation Nursing, 24(5), Pp 192-196

[5] McCullagh E, Brigstroke G; Determinants of care giving burden and quality of life in caregivers of stroke patients; Stroke 2005 Oct 36(10): 2181-86

[6] National Pressure Ulcer Advisory Panel, Pressure ulcers: Incidence, Economics, Risk Assessment, West Dundee, SN Publications; 2003, page no: 17-27.

[7] PeetersDuniel(1991 \& 2003); "Massage to prevent pressure ulcers “,Journal of Clinical nurse,Apr;15(4)428-35.

[8] Ragavan P. (2003); Prevalanve of pressure sores in a community sample of spinal injury patients" Clinical Rehabilitation, Dec; 17(8) Pp 879-882

[9] Joyce M. Black, Jane Hawks, Medical Surgical Nursing- Clinical Management for Positive Outcomes, 7th edition, Vol: II Page no: $1370-1433$

[10] Kozier \& Erab's; Fundamental of nursing concept, process \& practice, 8th edition,Berman shyder,Pp 904-907 